This item is the archived peer-reviewed author-version of:

Globalization and variants of local adaptation : theory and justification with symbolic logic

\title{
Reference:
}

Boone Christophe, Péli Gábor.- Globalization and variants of local adaptation : theory and justification with symbolic logic International sociology: journal of the International Sociological Association / International Sociological Association - ISSN 02685809 - 31:6(2016), p. 653-676

Full text (Publishers DOI): http://dx.doi.org/doi:10.1177/0268580916662384

To cite this reference: http://hdl.handle.net/10067/1390790151162165141 
International Sociology

\section{Globalisation and variants of local adaptation: Theory and justification with symbolic logic}

\begin{tabular}{|c|l|}
\hline Journal: & International Sociology \\
\hline Manuscript ID & IS-15-0078.R2 \\
\hline Manuscript Type: & Article \\
\hline Keywords: & Globalisation, Local adaptation, Logical Model, Contestation, Ideology \\
\hline Abstract: & $\begin{array}{l}\text { An increasing body of evidence indicates that globalisation can trigger a } \\
\text { variety of reactions from societies. The possible outcomes include blending, } \\
\text { hybridisation, fault line formation or even an increased salience of local } \\
\text { traditionalist value systems. An important task for the research field is } \\
\text { developing systematic, comparative theories predicting which outcome is } \\
\text { expected to emerge depending on the interplay between the global and the } \\
\text { local. Drawing on the rich empirical literature on globalisation variants, the } \\
\text { paper makes a further step in theory building proposing a typology with } \\
\text { the four possible outcomes mentioned above. To make the model premises } \\
\text { more transparent, we transcribe our arguments into symbolic logic } \\
\text { sentences and derive the typology outcomes as theorems. This allows } \\
\text { testing if the proposed model, indeed, implies the purported conclusions, } \\
\text { and to see what consequences would, or would not, follow from a slightly } \\
\text { modified premise set, that is, from a slightly modified globalisation theory. }\end{array}$ \\
\hline
\end{tabular}




\title{
Globalisation and variants of local adaptation: \\ Theory and justification with symbolic logic
}

\begin{abstract}
An increasing body of evidence indicates that globalisation can trigger a variety of reactions from societies. The possible outcomes include blending, hybridisation, fault line formation or even an increased salience of local traditionalist value systems. An important task for the research field is developing systematic, comparative theories predicting which outcome is expected to emerge depending on the interplay between the global and the local. Drawing on the rich empirical literature on globalisation variants, the paper makes a further step in theory building proposing a typology with the four possible outcomes mentioned above. To make the model premises more transparent, we transcribe our arguments into symbolic logic sentences and derive the typology outcomes as theorems. This allows testing if the proposed model, indeed, implies the purported conclusions, and to see what consequences would, or would not, follow from a slightly modified premise set, that is, from a slightly modified globalisation theory.
\end{abstract}




\section{Introduction}

Since the Second World War our world has witnessed massive increases in cross-border flows of goods, money, people, information and culture. This process, which goes hand in hand with rising interdependence and mutual awareness among economic, political, and social actors in the world, is generally referred to as globalisation. Although research shows that globalisation is a pervasive empirical reality (Brady et al., 2007; Meyer, 2000), at the same time it is one of the most contested topics in the social sciences (Guillén, 2001: 235). The debate and controversies in the literature relate to issues such as whether there is a global culture in the make, whether globalisation is always related to modernity and civilization and whether global convergence will ultimately undermine the authority of nation-states (Guillén, 2001; Schneiberg, 2006). Globalisation is without doubt a formidable blending force that blurs boundaries between different cultures (Robertson and Khonder, 1998). Through isomorphic processes common cultural models, values and practices organised in world discourse arise and penetrate social life worldwide in many areas of social life. For instance, numerous studies of the world-society research program of John Meyer and associates have demonstrated worldwide convergence of educational systems sharing a common rationalistic-scientific world culture stressing the importance of human rights and individual empowerment (Meyer et al., 1997, 2010; Bromley et al, 2011).

At the same time, however, a paradox of recent times emerges as such processes towards convergence often seem to go hand in hand with the growing importance of the particularities of local communities in shaping local cultural adaptations. More recent accounts, therefore, stress the dialectic tension between the global and the local arguing that global interdependence is not only a boundary-blurring force but may also demarcate boundaries between the global and the local even more sharply, for instance, when it represents a threat to local traditions (Marquis and Battilana, 2009: 284). Local actors and communities should not be portrayed as passive recipients of top-down institutional pressures and global values. Instead, this perspective underscores the importance of agency and contestation in whether actors are willing to adjust to these pressures (Divarci et al., 2015; Marquis and Battilana, 2009; Schneiberg, 2006). Globalisation involves the simultaneous operation of blending and segregating forces and "the interpenetration of sameness and difference - or in somewhat different terms, the interpenetration of universalism and particularism.” (Robertson and Khonder, 1998: 28). It should be understood as a complex process that simultaneously produces homogenization and 
heterogenisation (Brady et al., 2007: 317) and combines tendencies toward universalism and particularism.

The complex interaction between the global and the local also implies that the outcomes of globalisation are hard to predict. Local cultures may adapt or resist global phenomena, or might respond by mixing the global and the local resulting in hybrid adaptations to deal with globalisation pressures (Marquis and Battilana, 2009). In order to understand which local outcomes are likely to emerge in response to globalisation it is essential to chart the local characteristics that moderate the impact of globalisation. Surprisingly, however, there is not much systematic research on the implications of the interplay between the global and the local. What exactly are the outcomes of this interplay? When and how is tension resolved between the local and the global? What features are important in determining the specific outcomes of the globalisation process?

Our aim is contributing to theory building by addressing an array of such issues systematically. By doing so we respond to Guillén's plea (2009: 235) “for a comparative sociology of globalisation that is sensitive to local variations and to how agency, interest, and resistance mediate in the relationship between globalisation causes and outcomes". A next step in theorizing can be searching more order in these set of intriguing ideas. This can decrease the ambiguity of the arguments, which is a side effect of natural language theorizing. Some ambiguity is good - may argue many - as it keeps the door open for unforeseen ideas and interpretations. But conceptual vagueness is also bad - may add others -, because the halo of unspecified meaning associations around key concepts hinders proper information exchange, and lets discourse getting drown "in a sea of chewing gum" (Masuch and Lapotin, 1996). As theories develop the importance of disambiguation increases. Current globalisation theory has been reaching the state when systematization yields substantial benefits by offering a solid, though certainly not unchangeable, foundation for further conceptual work and empirical testing. Drawing on the insights of globalisation research, we identify different patterns of local cultural adaptation emerging as a result of the globalisation process. We also identify a parsimonious set of underlying conditions that lead to these patterns. Doing so, we propose a globalisation typology based on two dichotomic variables reflecting the localglobal interplay. First, we describe the typology in natural language. Then, we apply symbolic logic to build a transparent framework for the theoretical model. Logic is a powerful formal tool that supports qualitative theory development (Bruggeman and Vermeulen, 2002; Péli, 2016). Still, logic does not replace intuition; it does not tell the researcher what the important insights are. Logical modelling helps systematizing insights. 
Logic also facilitates arriving to new insights by exploring unforeseen consequences of the theoretical choices had been made. The pertaining arguments of the theory are one by one coupled to corresponding symbolic logic statements in a transparent manner, so that the theoretically oriented reader can evaluate the proposed globalisation model without being an expert in logic. The model we are going to present can also guide future empirical research by predicting specific consequences of the tension between the global and the local aspects of globalisation.

The rest of the article is organised as follows. To be able to contextualize our concepts and theory we proceed with a short State of the art section reflecting extant research on the outcomes of globalization, i.e., whether it leads to convergence or divergence that shape globalisation. Then drawing on this knowledge, we describe the main ideas behind the globalisation typology we are going to propose. After this phase, we translate this natural language rendering into logical formulae and derive the typology outcomes as theorems; to each we add interpretation, again, in natural language.

\section{State of the $\operatorname{art}^{1}$}

The question whether globalization leads to convergence among countries or not has dominated the globalization literature for decades (Berry et al., 2014). Many scholars have claimed that strong globalization mechanisms including competition, mimicry, emulation and coercion will eventually wipe out differences between countries, homogenizing political, economic and social institutions (e.g., Dobbin et al., 2007). This convergence thesis has been challenged by several other streams in the literature starting from the premise that "globalization is a fragmented, incomplete, discontinuous, contingent and in many ways contradictory and puzzling process" (Berry et al., 2014: 388; see also Giddens, 1990). Globalization in these accounts does not necessarily lead to convergence because, for instance, it is often incomplete not affecting all parts of the world uniformly (Ghemawat, 2003), because the path dependent nature of institutions and inertia result in persistent differences between countries (Katzenstein, 1985), and because globalization sometimes even spurs resistance (Zelner et al., 2009). World society scholars also argue that convergence is not complete as it confined to formal structures of nation states that adopt rationalized world models (Meyer et al., 1997). At the same time, however, structural similarity is decoupled from purpose and intention that are still shaped by local identity (Meyer, 2000). Finally, world-system theorists stress that globalization facilitates 
exploitative trade relationships between developing and developed countries ultimately leading to a cleavage between rich core- and poor peripheral countries (Bruton, 1998).

To settle this debate, a large number of empirical studies have been performed to look for evidence of convergence on several dimensions such as demographic, economic, financial, and political. "Most of these empirical studies find fragmentation and continuing heterogeneity, that is, little evidence of convergence across countries over time" (Berry et al., 2014: 388). This lack of evidence of convergence is, in general, consistent with the perspective that globalization is a fragmented and contingent process, the outcome of which depends on the complex interplay between the global and the local (Marquis et al., 2009; Robertson and Khonder, 1998). The model we present builds on this insight by specifying contingencies that affect when and where the globalization process leads to convergence or divergence.

\section{The model in natural language}

Consider a society exposed to the modernizing influence of globalisation. The local culture is predominantly traditional before globalisation arrives. Still, the modernisation ideas associated to globalisation have also followers. We are going to refer to the two groups representing, respectively, traditional and globalisation values as the traditionalist and moderniser fractions of this society. There are normally other important groups in societies; even our two fractions can be seen as aggregates of different sub-groups. Operating with these two broad fractions is a model constraint that allows spelling out our typology in a simple way, without excluding the possibility of later model refinement. The traditionalist and moderniser fractions have oppositional stance to each other, the degree of which may change as events unfold. Following the arguments in the Introduction, we propose two dimensions that influence globalisation's outcome: the cultural distance between modernizing ideas and local traditionalist ideas; and the intensity of contestation between adherents of local and global values. These dichotomic dimensions produce four types of cultural reactions to globalisation (Table 1).

\section{--- Table 1 comes about here ---}

The first dimension, cultural distance, reflects the content of globalisation, i.e., the type of universal ideas globalisation brings about. Specifically, some are cognitive/instrumental 
whereas others are more normative/ideological (Kern, 2010; Meyer, 2000). The cultural distance between global ideas and local traditionalist culture is substantially lower in the first case than in the second. This is because cognitive/instrumental ideas have a rational, scientific nature, as they tend to provide concrete solutions to particular problems. It is therefore easier to translate such ideas to local conditions and to assimilate them in the local traditional culture compared to normative/ideological ideas that are inherently valueladen and so subject to controversy. As Meyer observes (2000: 245): "globalization of instrumental culture is a striking empirical feature of the modern system, as models of proper actor hood for national states, individuals and organizations spread around the world". Indeed, scientific and instrumental rationality is so widespread because of their cognitive persuasiveness (Kern, 2010). In contrast, uniqueness and local identity often legitimately relates to issues of expressive culture, such as art, clothing and food, instead of rational actor hood, such as the identifying features of national educational systems.

The second dimension, the level of within-community contestation, relates to society's heterogeneity with respect to the values, global versus local, that are espoused. When a community is homogenous with respect to espoused ideas, then the contestation level is low. However, value heterogeneity is a necessary but not sufficient condition for experiencing a high contestation level in society. When this heterogeneity does not couple with the presence of significant oppositional fractions around these values, then observed contestation level is still low; not because of ideological consensus but because of the lack of strong and visible representatives of the differing ideas. But when significant groups also take oppositional stance along global and local values, this with heterogeneity forms a sufficient condition for a high level of societal contestation. So while cultural distance is about the size of the gap between local and global, the second dimension stands for the intensity of actual contestation between adherents of local and global values. The two dimensions yield four possible outcomes concerning the impact of the globalisation process (Table 1). All references to rows, columns and cells below concern this table in the rest of the paper. 
Table 1. Different local outcomes of the globalisation process.

2

3

4

5

6

7

8

9

10

\begin{tabular}{|c|c|c|}
\hline & $\begin{array}{l}\text { Low within-community } \\
\text { contestation }\end{array}$ & $\begin{array}{l}\text { High within-community } \\
\text { contestation }\end{array}$ \\
\hline $\begin{array}{l}\text { Low distance of global } \\
\text { ideas with local } \\
\text { traditional culture } \\
\text { Cognitive/instrumental } \\
\text { ideas }\end{array}$ & $\begin{array}{l}\text { 1. Accommodation or blending. } \\
\text { Reconciling local with } \\
\text { global. Local adoption of } \\
\text { universalism via } \\
\text { translation to local } \\
\text { conditions. }\end{array}$ & $\begin{array}{l}\text { 2. Hybridisation. } \\
\text { Combining specific } \\
\text { features of instrumental } \\
\text { universalism with local } \\
\text { tradition. }\end{array}$ \\
\hline $\begin{array}{l}\text { High distance of } \\
\text { global ideas with local } \\
\text { traditional culture }\end{array}$ & $\begin{array}{l}\text { 3. Saliency of the local. } \\
\text { Opposition against global } \\
\text { (out-group distancing). } \\
\text { Sharpening boundaries } \\
\text { between global and local. }\end{array}$ & $\begin{array}{l}\text { 4. Ideological partitioning. } \\
\text { Strong polarization and } \\
\text { distancing between } \\
\text { adherents of the local and } \\
\text { the global. }\end{array}$ \\
\hline
\end{tabular}


If there is no strong rivalry within the community, then ideological contestation about which ideas to adopt and to diffuse is low (first column). When the diffusing global ideas are also cognitive/instrumental (first row), most local carriers of ideas, be they individuals or organisations, will be persuaded to adopt these ideas (cell 1). These ideas will be translated for the locality, by taking into account the particularities of the local context, without much contestation. The outcome is a form of local adaptation as a result of which cultural distance between fractions decreases through adoption and learning. One way of decreasing distance is that fractions mutually adopt from each other. This can take place when the culturally different groups lack oppositional attitudes, letting them compromise and reconcile different viewpoints, and so blending the local with the global. Alternatively, cultural distance may decrease asymmetrically. This is the case when an initial oppositional stance between traditionalist and moderniser fractions hinders mutual value adoption.

When globalisation is not dominated by ideological values but rather by instrumental knowledge transmission (upper row), a strong modernisation fraction may impose globalisation values upon a weak, local traditional fraction, possibly even without resorting to force. In that case, the traditionalist fraction accommodates to globalisation values.

Blending and accommodation both involves cultural translation, with which genuinely new cultural ideas can be created. But unlike blending, accommodation does not imply that the moderniser side also adopts from traditionalists. In lack of reciprocation, accommodation is an asymmetric, one-sided form of local adaptation. The outcomes in cell 1 are those that are typically described by the world society perspective: by local blending and, especially, accommodation worldwide convergence and structural isomorphism emerges (Meyer et al, 1997). A case in point for accommodation is the development of post-war Japanese education. The tension between nationalism and cosmopolitanism in education caused by globalisation was solved by creating new educational solutions and categories such as the 'cosmopolitan Japanese' that reconciled the two institutional logics (Saito, 2011). Being defeated in war, the traditional society accepted an externally imposed Westernizing cultural impact, which was then rather technical, modernisation-oriented than ideologydriven. As a result of these, the Japanese educational system could adopt not only from the instrumental/technical, but also from the (non-aggressive) ideology aspects of the external influence. But accommodation does not necessary involve being defeated by the globalisation agents; think of the successful modernisation of South-Korea in the second half of the $20^{\text {th }}$ century. 
Next, we address the other case with low contestation in Table 1 (cell 3). Now, global cultural ideas are very distant from local traditions (second row); they are normative and ideology-laden such as rights for gay people, or the issue of euthanasia. But in spite of the unbridgeable ideological differences, the contestation level is still low (first column). The moderniser fraction is though present but not significant; therefore within-community contestation is also weak. In lack of a massive carrier of globalisation ideas and in the presence of strong local traditionalists, ideology-driven globalisation cannot penetrate. The case of cell 3 demonstrates that low societal level contestation does not necessarily mean harmony or peace between heterogeneous ideas; it can also mean radically unequal societal impacts of the opposing ideas, for example, if one is effectively suppressed by the other. Still, the appearance of value-laden globalisation ideas by even an insignificant and marginalised moderniser fraction can generate a contrast effect. This contrast renders the dominating traditionalist values even more visible - salient - in society. Salience reinforces boundaries between global ideas and local traditions. A case in point is the growing cultural opposition of fundamentalist countries against the diffusion of the Western global model of modernisation in the past decades. The moderniser groups are suppressed and marginalised. Still their values can be well used by local authorities to demonstrate a negative example for the populace, and so to better underscore the necessity of strict adherence to fundamentalist traditionalism. The Taliban rule in the pre-2002 Afghanistan and the recently emerged Islamic State exemplify extreme salience of anti-globalisation values. The cultural distance between fundamentalist mind-sets and globalisation ideas is huge; even the mildest secular aspects of modernisation are banned; extremist religious views have become salient.

The remaining cells 2 and 4 in Table 1 reflect cases of intense contestation between the local and the global, resulting in a fault line formation in society. The development and also the 'maintenance' of the fault line, however, take place by different mechanisms in the two. In both cases, the two fractions are not only oppositional but also significant, with these two jointly leading to intense contestation (second column). Making a distinction between competition for resources and ideological contestation is an important feature of our model. Contestation may take place with or without direct competition for scarce resources between opponents. Accordingly, the potential tension between modernisers and traditionalists may or may not involve niche overlap in a socio-economic or political sense (Carroll et al., 2002; Otjes et al., 2013). Contestation can take place even between groups that do not go for the same resource, and so have no niche overlap. For example, a middle right political party may have a competitive niche overlap with a centrist party as the two go for somewhat similar moderate voters. But the same middle right party has no common voter base whatsoever (has no competitive overlap) with a radical left party, even if they 
fiercely contest each other in the political arena. Cells 2 and 4, respectively, represent cases of strong contestation with and without competitive interactions between traditionalists and modernisers.

In cell 2 of Table 1, the fault line between fractions is maintained by bybridisation. The instrumental value aspects of globalisation like technical development and related knowledge transfer may also be appealing for many traditionalists, who are willing and capable to embrace the scientific and technical developments associated with modernisation while maintaining their devotion to their traditional cultural background. When globalisation poses a developmental pressure on a society of significant traditionalist presence, these pragmatist traditionalists may become the proponents of adopting the technical aspects of modernisation. So the traditionalist fraction adopts from the instrumental aspects of globalisation when deeming these aspects useful, and when the non-ideological character of globalisation (first row) makes its potential knowledge transfer separable from its now relatively mild ideological component. Then, locals can pick up the 'good stuff' from globalisation without too much compromise concerning their adherence to traditional values (Schofer et al., 2000), resulting in decoupling between formal structure and purpose which has also been described by 'world society' scholars (Meyer et al., 1997). As a result, instrumental global forces create opportunities to build hybrid institutions and organisational forms (Haveman and Rao, 2006). Hybrid forms assemble elements from universalistic forms with elements from particularistic local forms. The resulting new form combines its own, traditional values with new features in an additive way, without full adoption and translation of the others' values. Hybrids, however, face unique obstacles as they are often penalised by audiences because they blur the boundaries of taken-forgranted forms challenging their legitimacy (Negro et al., 2010; Minkoff, 2002; Rao et al., 2005). Therefore, considerable effort is needed to mobilise actors to establish these atypical entities. Competition for resources is such a mobilizing force: hybridisation supplies traditionalists with the skills to fight modernisers and to handle this threat. The result is an ongoing competition, which sustains the fault line along ideological aspects while makes fractions more similar along technical aspects. This case fits with the emergence of the socalled Anatolian Imam Hatip schools in Turkey that combine features of the old Turkish secular gymnasia with traditional religious education (Divarci et al., 2015). This hybrid form emergence is fuelled by the strong competition between secular and religious people for a scarce resource: elite positions in society. The Anatolian Imam Hatip Schools involved modern curricular elements, while clearly maintaining their Muslim identity emphasizing the traditional religious aspects in their curricula. Nevertheless, reaping the instrumental 
benefits of globalisation presumes that these aspects are somehow separable from globalisation's ideological content. Other examples of hybridisation are provided by Pakistan, or by nowadays Iran, both assumed developing a nuclear potential. Their governments support the adoption of Western nuclear technologies in order to keep their competitive positions in military aspects. In the meanwhile, they vigilantly defend, though in different measures, their religious society from Western ideological influence. Nuclear technology is a modernisation product that can be adopted without adopting from the political ideology of those who had first developed this technology.

The separability of instrumental and normative value aspects is certainly not the case, however, when globalisation is dominantly ideology-driven (second row). In combination with a high contestation level (second column), this brings us to the fourth cell of the typology. Now, the societal fault line corresponds to a deadlock: two significant fractions stand against each other at the opposite sides of a deep cultural ditch. The emerging ideological partitioning prevents learning and adopting from each other. What makes the difference between hybridisation and ideological partitioning is the degree of cultural distance. Ideological partitioning can prevent the separate adoption of instrumental modernisation aspects. The case of cell 4 is akin to a sustainable bifurcation between local traditionalists and modernisers. The Stalinist period of Soviet rule exemplifies a case when the ideology-driven attitude was at the local, anti-globalisation side. In spite of its harsh 'world revolution' ideology and propaganda, the Soviet Union was very much closed from external influence (except for the war-period when the regime had to show some shortterm ideological elasticity for survival reasons). The cultural schism between Stalinist orthodoxy and Western influence had become so large that prevented the adoption of a broad array of technical/instrumental modernisation aspects: disciplines like genetics, sociology and computer science had been stigmatised as 'bourgeois pseudo-science'. A specific feature of this example is that the partitioning had not taken place within the same society but between countries. ${ }^{2}$ A societal level example of ideological partitioning is provided by the decade long, recurrent contestation between polarized secular and religious fractions in modern Turkey about the role of religion in public life and education emanating in fierce debates about, e.g., the wearing of headscarves in public life (Divarci et al., 2015; Guven, 2005). ${ }^{3}$ 


\section{The model in symbolic logic}

\section{The role of logical model building}

Formal methods and qualitative methods are oftentimes, but incorrectly, considered as antinomies. Our method, logical modelling provides a formal but still qualitative approach to derive conclusions from theoretical arguments put forward in a natural language. In the course of model specification, we provide the reader with the logic essentials necessary to evaluate our findings. Theory development normally does not follow the rules of a clearcut derivation. The initial phases of theoretical model building are normally based on pictures, metaphors and visualizations. But once our mental framework has been established, systematic specification gains importance. When researchers want to have a clear view on the inference structure of their work, logical modelling may step in. Logical formalization translates the theory's premises and conclusions, originally all formulated in natural language, into a set of symbolic logical sentences. Then, attempts can be made to derive the theory's conclusions from these premises as theorems. This proof phase is supported by user-friendly theorem-prover softwares also accessible for the non-technically oriented reader (cf. Appendix 1). Is there is sufficient information in the premise set to support our particular conclusions? If not, search can begin for additional, or for stronger, premises that patch up the information gap. Logical formalization may also support potential model generalization by helping to test if we get the same conclusions from a weaker set of premises. If we agree with the statements of the premises, then we can be sure about the validity of the conclusions derived from them. This feature has beneficial impacts on scientific discussion. The protagonists can put forward their arguments in a straightforward manner, while the antagonists of a derived outcome can put their fingers on the particular premises (definitions or assumptions) they would not accept. Attempts can be made to see what conclusions would follow from modified, now consensually accepted premises. The added value of logical modelling is arriving to a theory with more solid foundations, with a more transparent and parsimonious argumentation structure, and with the possibility of deducing new conclusions from the established (or extended) premise set. We apply a simple and powerful logical system, classical First-Order Logic (Gamut, 1991; Kamps and Pólos, 1999; Péli, 2009). ${ }^{4}$ 
Next, we step by step translate the natural language model into a formal one. We begin the model specification with coming up with symbolic logic counterparts for the natural language descriptions of the basic concepts. Then we put a number of assumptions forward that connect these concepts. This brings to a premise set strong enough to imply the predictions in cells 1-4 of Table 1 as theorems.

--- Tables 2-3 come about here ---

\section{Basic concepts and their relations}

The basic logical symbols and the vocabulary of our formal language are displayed in Table 2. All model assumptions referred from now on are displayed in Table 3, while Table 4 (below) displays the definitions. An English language 'read' follows each symbolic logic sentence. These 'reads' obtain by instantiating the pertaining symbol descriptions in Table 2 into the formulae. With this instantiation properly done, we arrive to grammatically correct, though maybe not very elegant, English sentences.

The unit of our analysis is yet traditional society subject to an externally given globalisation impact at the time of our investigation. We consider the existence of two distinct cultural value sets: modernisation values and traditional values. Assumption 1 states that cultural values are either modernisation values or traditional values. Assumption 2 claims that modernisation value sets can be categorised as ideological (Ideol) or instrumental (Instrum). Assumption 3 adds that Ideol and Instrum are the only modernisation value types of the model. Traditional values may also differ; but as the typology outcomes (Table 1) can be derived even without making distinction between traditional values, we need not introduce symbolic logic constructs for them in the current phase of theory specification. We also assume the presence of two societal fractions, the modernisers $(M)$ who embrace modernisation values, and the traditionalists $(T)$ carriers of local traditionalist values (Assumptions 4-5). Next, Assumption 6 associates cultural values with fractions, stating that traditionalists are adopters of traditional values while the modernisers are adopters of modernisation values. Fractions $T$ and $M$ take oppositional stance towards each other (Assumption 7). We briefly address the case of non-oppositional contexts in Appendix 2. We also make explicit two aspects of tacit knowledge: being oppositional is a symmetric and irreflexive relation, the latter meaning that no fraction is oppositional to itself (Assumption 8). 
Table 2. Logical symbols and vocabulary items.

Logical connectives, in order of their decreasing binding strength. ${ }^{\text {a }}$

$\neg$ (negation), $\wedge$ ('and'), $\vee$ (inclusive 'or'), $\rightarrow$ (implication, 'if ... then'), $\leftrightarrow$ (bi-implication, 'if and only if')

\section{Quantifiers $^{\mathrm{b}}$}

$\forall$ (universal quantifier, 'for all'), $\exists$ (existential quantifier, 'there exists').

\section{Predicates}

$\operatorname{Accomm}(x)$

$\operatorname{Adopt}(x, y)$

Contest $(x)$

CultVal $(x)$

$\operatorname{Dom}(x)$

Fraction $(x)$

Hybrid $(x)$

IdeolPart

Id_Driven

Instrumental

$\operatorname{ModVal}(x)$

$O p p(x, y)$

$\operatorname{Press}(x)$

Salient $(x)$

$\operatorname{Sign}(x)$

Separable $(x, y)$

$-x$ accommodates other values

$-x$ adopts $y$

$-x$ is the level of contestation in society

$-x$ is a cultural value in society

$-x$ is dominant in society

$-x$ is a fraction of society

TradV Val $(x)$

- Hybridisation of $x$ takes place

- There is an ideological partitioning in society

- Globalization is ideology driven

- Globalization is instrumental value driven

$-x$ is a modernization value in society

$-x$ and $y$ are in opposition

$-x$ is exposed to pressure

$-x$ is salient in society

$-x$ is significant in society

$-x$ and $y$ are separable

$x>y$

$-x$ is a traditional value in society

$-x$ is greater than $y$

\section{Proper names}

$T$

M

Instrum

Ideol

- The traditionalist fraction

- The modernizer fraction

- The instrumental values of globalization

High, Low

- The ideological values of globalization

${ }^{a}$ For example, $A \wedge B \vee C$ is equivalent to $(A \wedge B) \vee C$ because ' $\wedge$ ' binds stronger than ' $\vee$ '. Just in mathematics, the binding strength order can always be overridden by using parentheses.

b The scope, or range of application, of a quantifier is indicated by square brackets: [... ]. We also adopt the convention of omitting universal quantification $(\forall)$ from the beginning of formulae. 
Table 3. Model assumptions.

Assumption 1. $\quad \operatorname{CultVal}(\mathrm{x}) \rightarrow \operatorname{ModVal}(\mathrm{x}) \vee \operatorname{TradVal}(\mathrm{x})$

( $x$ is a cultural value, if and only if, $x$ is either a modernisation value or $x$ is a traditional value.)

Assumption 2. $\quad \operatorname{ModVal}($ Instrum $) \wedge \operatorname{ModVal}($ Ideol $)$

(Instrum and Ideol are modernisation values.)

Assumption 3. $\quad \operatorname{ModVal}(\mathrm{x}) \rightarrow(\mathrm{x}=$ Instrum $) \vee(\mathrm{x}=$ Ideol $)$

(If $x$ is a modernisation value, then $x$ is either identical to Instrum or $x$ is identical to Ideol.)

Assumption 4. Fraction $(\mathrm{T}) \wedge$ Fraction $(\mathrm{M})$

( $T$ and $M$ are fractions in society.)

Assumption 5. Fraction $(\mathrm{z}) \rightarrow(\mathrm{z}=\mathrm{T} \vee \mathrm{z}=\mathrm{M})$

(If $x$ is a fraction, then $x$ is identical either with the traditionalist fraction or with the moderniser fraction

Assumption 6. $\quad(\operatorname{ModVal}(\mathrm{x}) \rightarrow \operatorname{Adopt}(\mathrm{M}, \mathrm{x})) \wedge(\operatorname{TradVal}(\mathrm{y}) \rightarrow \operatorname{Adopt}(\mathrm{T}, \mathrm{y}))$

(If $x$ is a modernisation value, then $M$ adopts $x$, and if $y$ is a traditional value, then $T$ adopts $y$.)

Assumption $7 . \quad \mathrm{Opp}(\mathrm{T}, \mathrm{M})$

(Fractions $T$ and $M$ are oppositional to each other.)

Assumption 8. $\quad \mathrm{Opp}(\mathrm{x}, \mathrm{y}) \rightarrow \mathrm{Opp}(\mathrm{y}, \mathrm{x}) \wedge \neg \mathrm{Opp}(\mathrm{x}, \mathrm{x})$

(If $x$ is oppositional to $y$, then $y$ is oppositional to $x$, and $x$ is not oppositional to $x$.)

Assumption 9. Instrumental $\leftrightarrow \neg$ Id_Driven

(If globalisation is instrumental, then it is not ideology driven.)

Assumption 10. Instrumental $\leftrightarrow$ Separable(Instrum, Ideol)

(Globalisation is instrumental, if and only if, its instrumental and ideological values are separable.)

Assumption 11. Contest(High) $\leftrightarrow \neg$ Contest(Low)

(The level of contestation is high in society, if and only if, the level of contestation is not low.)

Assumption 12. Id_Driven $\wedge \operatorname{TradVal}(\mathrm{x}) \rightarrow \neg \operatorname{Adopt}(\mathrm{M}, \mathrm{x})$

(If globalisation is ideology driven and $x$ is a traditional value, then $M$ does not adopt $x$.)

Assumption 13. $\quad \operatorname{Opp}(\mathrm{T}, \mathrm{M}) \wedge \operatorname{Sign}(\mathrm{T}) \rightarrow \neg \operatorname{Adopt}(\mathrm{T}, \mathrm{Ideol})$

(If fractions $T$ and $M$ are oppositional and $T$ is significant in society, $T$ does not adopt the ideological values of globalisation.)

Assumption 14. $\quad$ Press $(T) \rightarrow($ Adopt(T, Instrum) $\leftrightarrow$ Separable(Instrum, Ideol) (If $T$ is under pressure, then $T$ adopts Instrum, if and only if, Instrum is separable from Ideol).

Assumption 15. $\neg$ Id_Driven $\wedge \operatorname{Dom}(\mathrm{M}) \wedge \operatorname{ModVal}(\mathrm{x}) \rightarrow \operatorname{Adopt}(\mathrm{T}, \mathrm{x})$

(If globalisation is not ideological value driven, and modernist fraction $M$ is dominant in society and $x$ is a modernisation value, then traditionalist fraction $T$ adopts $x$.) 
A fraction may play a significant role in society. Significance indicates the fraction's strong position and impact, either because of its size or because of its intense societal presence. Small but hyperactive societal groups may exemplify the latter case of significance. Significance enables exercising pressure on opponents, a concept that we can now formally define with the vocabulary built up so far (Definition 1$)^{5}$

--- Table 4 comes about here ---

Next, we define dominance. A fraction plays a dominant role in society when it is the only significant fraction around (Definition 2). While exercising pressure may be symmetric, dominance is asymmetric. Note that Definition 2 does not stipulate oppositional stance; thus it also allows for 'friendly dominance', a concept that might be useful at a later exploration of globalisation under cooperative conditions, think of how the dominant role of United States is perceived by some of its allies.

Now comes the translation of the two main globalisation dimensions of Table 1 into symbolic logic. The vertical dimension, cultural distance, was conceptualised with reference to the cognitive/instrumental versus normative/ideological loads of globalisation. When globalisation is ideology-driven, cultural distance between global and local is large; when globalisation is dominated by instrumental aspects, cultural distance is smaller. Assumption 9 expresses this dichotomy by stating that the globalisation impact is driven by only one of these two. As argued before, adopting the technical aspects of modernisation can keep traditionalists competitive with challenger modernisers. But technical adoption hinges upon a condition: the instrumental aspects of globalisation should be decoupled from its ideological content. When globalisation is driven by instrumental aspects rather than ideological ones, the tension between globalisation and traditional locality is not extreme. In that case, and only in that case, the possibly acceptable and the definitely opposed globalisation aspects do not come in one 'take it or leave it' package. This is summarised by Assumption 10 positing that under instrumental globalisation, the instrumental values are separable from the ideological aspects. 
Table 4. Definitions.

Definition 1. Pressure on a fraction.

Fraction $(\mathrm{x}) \rightarrow(\operatorname{Press}(\mathrm{x}) \leftrightarrow \exists \mathrm{y}[\operatorname{Fraction}(\mathrm{y}) \wedge \operatorname{Sign}(\mathrm{y}) \wedge \mathrm{Opp}(\mathrm{x}, \mathrm{y})])$

(If $x$ is a fraction, then $x$ is under pressure, if and only if, there exists $y$ such that $y$ is a fraction, significant and oppositional to $x$.)

\section{Definition 2. Dominant fraction.}

$\operatorname{Fraction}(\mathrm{x}) \rightarrow(\operatorname{Dom}(\mathrm{x}) \leftrightarrow \operatorname{Sign}(\mathrm{x}) \wedge \neg \exists \mathrm{y}[\operatorname{Fraction}(\mathrm{y}) \wedge \operatorname{Sign}(\mathrm{y}) \wedge \neg(\mathrm{x}=\mathrm{y})])$

(If $x$ is a fraction, then $x$ is dominant, if and only if, $x$ is significant, and there exists no $y$ such that $y$ is a fraction, significant and not identical to $x$.)

Definition 3. High level of contestation. Contest(High) $\leftrightarrow$

$\exists \mathrm{x}, \mathrm{y}[\operatorname{Fraction}(\mathrm{x}) \wedge \operatorname{Fraction}(\mathrm{y}) \wedge \operatorname{Opp}(\mathrm{x}, \mathrm{y}) \wedge \operatorname{Sign}(\mathrm{x}) \wedge \operatorname{Sign}(\mathrm{y})]$

(The level of contestation is high, if and only if, there exists $x$ and $y$, such that $x$ and $y$ are fractions in society, oppositional to each other and both significant.)

Definition 4. Accommodation of traditionalists.

$\operatorname{Accomm}(T) \leftrightarrow \forall x[\operatorname{ModVal}(\mathrm{x}) \rightarrow \operatorname{Adopt}(\mathrm{T}, \mathrm{x})]$

( $T$ accommodates other values, if and only if, for all $x$, if $x$ is a modernisation value, then $T$ adopts $x$.)

\section{Definition 5. Hybridisation.}

$\operatorname{Hybrid}(T) \leftrightarrow \operatorname{Sign}(T) \wedge \exists x, y[\operatorname{ModVal}(\mathrm{x}) \wedge \operatorname{ModVal}(\mathrm{y}) \wedge \operatorname{Adopt}(\mathrm{T}, \mathrm{x}) \wedge \neg \operatorname{Adopt}(T, \mathrm{y})]$

(Hybridisation of $T$ takes place, if and only if, $T$ is significant, and there exist modernisation values $x$ and $y$ such that $T$ adopts $x$, and $T$ does not adopt $y$.)

Definition 6. Salience of a cultural value. $\quad \operatorname{CultVal}(\mathrm{x}) \rightarrow($ Salient $(\mathrm{x}) \leftrightarrow$ $\exists \mathrm{z}[\operatorname{Fraction}(\mathrm{z}) \wedge \operatorname{Dom}(\mathrm{z}) \wedge \operatorname{Adopt}(\mathrm{z}, \mathrm{x}) \wedge \forall \mathrm{y}[\operatorname{Fraction}(\mathrm{y}) \wedge \operatorname{Opp}(\mathrm{z}, \mathrm{y}) \rightarrow \neg \operatorname{Adopt}(\mathrm{y}, \mathrm{x})]])$

(If $x$ is a cultural value, then $x$ is salient in society, if and only if, there exists a dominant fraction $z$ and $z$ adopts $x$, and all fractions $y$ oppositional to $z$ do not adopt $x$.)

\section{Definition 7. Ideological partitioning.}

IdeolPart $\exists x$, y $[$ Fraction $(x) \wedge \operatorname{Fraction}(y) \wedge \operatorname{Opp}(x, y) \wedge \operatorname{Sign}(x) \wedge \operatorname{Sign}(y) \wedge$

$$
\neg \exists \mathrm{z}[\mathrm{Cult} \operatorname{Val}(\mathrm{z}) \wedge \operatorname{Adopt}(\mathrm{x}, \mathrm{z}) \wedge \operatorname{Adopt}(\mathrm{y}, \mathrm{z})]]
$$

(There is an ideological partitioning in society, if and only if, there exist fractions $x$ and $y$, oppositional and significant, and there exists no cultural value $z$ adopted by $x$ and by $y$.) 
The horizontal dimension of the typology in Table 1 is represented by the high/low levels of contestation between fractions (Assumption 11). High contestation level in society comes together with intense rivalry for ideological dominance, political power and control. High contestation also means strong societal tension, which can only build up with significant opponents in place. Accordingly, we define high contestation level with the existence of significant oppositional fractions (Definition 3).

\section{Typology outcomes}

We have now all the formal components in place to define the four typology outcomes displayed in Table 1. Local adoption (cell 1) involves that the cultural difference between fractions will lessen along both ideological and instrumental value aspects. Traditionalists and modernisers have already adopted, respectively, their 'own' traditionalist and moderniser values (Assumption 6); thus, getting closer can only takes place by adopting from the other. As indicated in the Introduction, the present model addresses asymmetric local adaptation, accommodation: traditionalists adopt moderniser values, potentially without modernisers' adoption from traditionalists. Accordingly, Definition 4 characterises traditionalists' accommodation to globalisation by their adoption of modernisation values. The other outcome in cell 1, blending, may occur if allowing for non-oppositional, cooperative attitudes between fractions; see more on this in Appendix 2.

Hybridisation (cell 2) takes place when a significant fraction adopts some, but not all, aspects of globalisation. The result is that the two oppositional fractions get closer along this particular modernisation aspect, while their cultural gap sustains along other modernisation aspects. In the current globalisation context, hybridisation means that traditionalists adopt the technical aspects of modernisation. Definition 5 captures this by requiring the existence of modernization values $x$ and $y$, from which only $x$ is adopted by $T$. The hybridising fraction is assumed to have a significant role in society; this is because when an insignificant group hybridises, the macro-level competition impact is ignorable. ${ }^{6}$

A salient cultural value (cell 3) in society sticks out from the background with its importance and visibility. A cultural value can reach salient status if dominant actors in society 'put it upfront' by adopting and representing it. Definition 6 on salience first stipulates that the 
concept applies to cultural values. Second, salience requires that some dominant fraction ₹ adopts, and so manifests, this value. Finally, the definition demands that no oppositional fraction adopts this cultural value. Note that the presence of even a non-significant fraction with different values may make the contrast between the salient value and the rest sharper. ${ }^{7}$

An ideological partitioning in society (cell 4) assumes the presence of strong opponents that have no relevant aspects in common. The right-hand side of Definition 7 first fixes the presence of significant fractions $x$ and $y$ of oppositional stance, while the rest posits the non-existence of cultural value $z$ adopted by both. Ideological partitioning exemplifies an even a stronger division line in society than hybridisation. Now, the separation along ideological aspects is so deep that precludes any communion with the other side. The landscape is frozen, with two strong fractions looking at each other with animosity on the two sides of the trench.

\section{Premises on value adoption}

The rest of the assumptions characterise how fractions react to globalisation. Value adopting behaviour is contingent upon two aspects: the fraction's position in society (significant or not) and on the degree of cultural distance. When fractions have cooperative attitude, adoption from the other may take place by free will. But in the present oppositional context (Assumption 7), value adoption from the opponent needs a pressing reason. This reason can either be the insignificant, underdog position of the adopting fraction (accommodation) or some rational calculations that indicate benefits from adoption (hybridisation). The next premises reflect these considerations.

Modernisers are the proponents of globalisation; if globalisation is ideology-driven, then modernisers would resist adopting from traditional values (Assumption 12). Traditionalists are challenged by globalisation. Their adaptive or refusing behaviour concerning modernisation values will depend on the societal context. The latter is captured by three premises. The first posits that when oppositional to modernisers and also significant enough to resist, traditionalists do not adopt the (for them: alien) ideological aspects of globalisation (Assumption 13). But when facing pressure from moderniser opponents, traditionalists may well adopt the knowledge-related instrumental aspects of globalisation. A precondition of this, however, is that globalisation's instrumental aspects are separable from its ideological load (Assumption 14). The third premise concerns traditionalists' reaction to globalisation from a weak, submissive position. When being dominated by 
modernisers, traditionalists may give in and adopt from globalisation's instrumental and ideological aspects both. Again, a precondition is that globalisation is not ideology-driven, so that its pragmatic flavour sweetens the pains of value adoption. Assumption 15 depicts a case of triumphant modernisation: under moderniser dominance, traditionalist fraction $T$ adopts all aspects of an ideologically light version of globalisation.

\section{Theorems}

The premise set now contains enough information to derive the predictions of the globalisation typology (Table 1). For each theorem, we list the subset of premises actually mobilised at proving that particular theorem. The proofs have been provided by the Prover 9 and Mace4 online available theorem prover softwares (McCune, 2015). The use of theorem provers, rigorous by nature, can be a help on at least two accounts. The first is avoiding overlooking pieces of information necessary for a correct proof; the second is potentially identifying premises of the theory that are not necessary for the proof of a particular theorem (though it might be necessary at others). While the first case indicates the need to feed in more information by adding model constraints, the second indicates possible theory generalizations through releasing constraints. By identifying the formulae mobilised at a particular proof, the reader gets a picture about the 'price' expressed in terms of model constraints at which the given theorem is obtained. Thus an extant logical formalization can always be seen as a benchmark for potential improvements. The interested reader might play around with the model, trying to get the same, or even other, results from conveniently modified constraints. To facilitate experimentation, we give the theorem prover-ready version of our logical model in Appendix 1. Our premise set represents our bid. Let's see how far we can get with it. Theorems 1-4 below reflect the model's four main predictions summarized in Table 1.

Theorem 1. Accommodation. (From Definitions 2-4, Assumptions 4, 5, 7, 9, 11 and 15.)

When globalisation is driven by instrumental aspects, contestation level is low and modernisers are significant, traditionalists accommodate other values. ${ }^{8}$

Instrumental $\wedge$ Contest $(\operatorname{Low}) \wedge \operatorname{Sign}(M) \rightarrow A \operatorname{ccomm}(T)$

Theorem 1 is restricted to contexts when significant modernisers interact with insignificant traditionalists. The not too large cultural distance associated to instrumental value driven globalisation makes the value adoption for traditionalists easier. 
Theorem 2. Hybridisation. (From Definitions 1, 3, 5, Assumptions 2, 5, 8, 10, 13 and 14.)

When globalisation is driven by instrumental aspects and contestation level is high, traditionalists hybridise.

Instrumental $\wedge$ Contest $($ High $) \rightarrow$ Hybrid $(T)$

Now, strong contestation indicates having two significant opponents around (Definition 3) that keep each other under mutual pressure (Definition 1). Both fractions can make good use of the instrumental advantages of globalisation. But for traditionalists, adopting the instrumental aspects requires the separability of the instrumental and ideological aspects (Assumption 14). This separability is granted by the instrumental character of globalisation (Assumption 10). This allows traditionalists to hybridise, utilizing instrumental globalisation benefits at their competition with modernisers while still not adopting globalisation's ideological content (Assumption 13).

Theorem 3. Traditional value salience. (From Definitions 2, 3, 6, Assumptions 1, 4-7, 11 and 12.) When globalisation is ideology-driven, contestation level is low and traditionalists are significant, traditional values become salient in society.

Id_Driven $\wedge$ Contest $(\operatorname{Low}) \wedge \operatorname{Sign}(T) \wedge \operatorname{TradV} \operatorname{Val}(x) \rightarrow \operatorname{Salient}(x)$

Low contestation involves that only one fraction can be significant (Definition 3). Because of this asymmetry, the significant $T$ is also dominant (Definition 2). This dominant position of $T$ gives importance to the traditional values it represents (Assumption 6). The ideologydriven character of globalisation prevents modernisers from adopting traditionalist values (Assumption 12). This state of affairs guarantees the constituent property of salience: the salient cultural values are featured by the dominant fraction (Definition 6). Now, the ideology-driven globalisation cannot make a strong foothold in society. The insignificant but ideologically exposed moderniser fraction still has a role: its presence makes a sharp societal contrast with traditionalism, thus making the prevailing traditionalist values even more visible - salient - in society.

Theorem 4. Ideological partitioning. (From Definitions 1, 3, 7, Assumptions 1, 3, 5, 7- 10, 12-14) When globalisation is ideology-driven and contestation level is high, an ideological partitioning takes place in society.

Id_Driven $\wedge$ Contest $($ High $) \rightarrow$ IdeolPart 
High contestation level means that the fractions are significant and also oppositional (Definition 3). Globalisation is ideology-driven; so adopting its instrumental aspects in separation from the ideological content is not possible (Assumptions 10,14). The ideologydriven modernisers do not adopt from the traditionalists either (Assumption 12). Consequently, the strongly contesting fractions do not converge along any aspects. An impasse occurs, with an ideological partitioning between strong and intransigent opponents. It may still be a question how stable this impasse can be. The instrumental aspects of globalisation may yield a competitive advantage to modernisers above nonadopting hard-liner traditionalists. This suggests that such ideological partitioning can only be stable if some yet unspecified effects working in favour of traditionalists (external to our model to the moment) stabilise it. Putting differently, these traditionalists need some isolation mechanism that inhibits modernisers outcompeting them with their technical superiority. Identifying such mechanisms is another topic for future research.

\section{Concluding remarks}

We put forward a theory explicating how local contexts interact with globalizing forces. Globalisation's impact depends on two major features of local communities, the saliency of which has been emphasised in past literature (Meyer, 2000; Marquis and Battilana, 2009): on the cultural distance between local and global values, and on the contestation intensity between adherents of local and global values.

With applying symbolic logic, our goal was making a step towards conceptual solidification of vivid and insightful theoretical ideas put forward by the globalisation research of the last decade. Although our theory allows capturing several important outcomes of globalisation discussed in the literature, our logical rendering is certainly not - and does not intend to be - the final word in the ongoing discussion about globalisation. Once a conclusion is derived, opponents of this conclusion can survey the premise list for items they deem unacceptable. Experimentation then can begin with more 'pleasing' modified premises, seeing how far one can get with them in terms of theoretical conclusions. The ongoing reformulations may lead to consensual solutions, just like when theorizing in natural language. Accommodation, blending, hybridisation, value salience, and ideological partitioning are characteristically different ways how local communities react to globalisation. Our theory allows to predict which particular outcome would emerge. But as the proof of the pudding is in the eating, systematic comparative, empirical research is 
needed to test the major predictions. Also here much work remains to be done, since systematic empirical research into the interplay between the global and the local is yet scarce. Recently, however, scholars have taken up this challenge showing the feasibility of this kind of empirics-driven theoretical investigation (Boone and Özcan, 2015; Divarci et al., 2015).

We started the paper by observing that globalization is a pervasive empirical reality as exemplified by the growing interconnectedness in different domains of our lives, i.e., economic, political and social/cultural. As a first start, we did not distinguish between these different domains, instead focusing on the aggregate effects of globalization. One future research pathway to follow is disentangling the interplay between social, economic and political aspects of globalization, exploring how it affects the globalization outcomes we discussed in this paper. Another line of research could be surpassing what economists call comparative statics and addressing the dynamics that forms and sustains the categories in the typology. How do persons and social groups move between categories, so shaping and possibly blurring them? Such efforts hold much promise as they would increase our understanding of globalisation, a phenomenon that is complicated and contested but certainly of utmost importance in modern times. 


\section{References}

Berry H, Guillén MF and Hendi AS (2013) Is there convergence across countries? A spatial approach. Journal of International Business Studies 45: 387-404.

Boone C, Özcan S (2015) Blending, segregating and hybridization: A country-level study of the founding of Islamic banking windows, 1975-2015. ACED working paper, University of Antwerpen, Belgium.

Brady D, Beckfield J and Zhao W (2007) The consequences of economic globalization for affluent democracies. Annual Review of Sociology 33: 313-334.

Bromley P, Meyer JW and Ramirez FO (2011) Student-centeredness in social science textbooks, 1970-2008: a cross-national study. Social Forces 90: 547-570.

Bruggeman JP, Vermeulen I (2002) A logical toolkit for theory (re)construction. Sociological Methodology 32: 183-217.

Bruton HJ (1998) A reconsideration of input substitution. Joumal of Economic Literature 36: 903-936.

Carroll GR, Dobrev SD and Swaminathan A (2002) Organizational processes of resource partitioning. Research in Organizational Behavior 24: 1-40.

Divarci A, Boone C and Witteloostuijn A van (2015) When does globalization lead to local adaptation? The emergence of hybrid Islamic schools in Turkey. ACED working paper, University of Antwerpen, Belgium.

Dobbin F, Simmons B and Garret C (2007) The global diffusion of public policies: Social construction, coercion, competition, or learning? Annual Review of Sociology 33: 449-472.

Gamut LTF (1991) Logic, Language and Meaning: Introduction to Logic. Chicago: Chicago University Press. 
Ghemawat P (2003) Semiglobalization and insternational business strategy. Journal of International Business Studies 34: 138-152.

Giddens A (1990) The Consequences of Modernity. Stanford: Stanford University Press.

Guillén MF (2001) Is globalization civilizing, destructive or feeble? A critique of five key debates in the social science literature. Annual Review of Sociology 27: 235-260.

Guven I (2005) The impact of political Islam on education: The revitalization of Islamic education in the Turkish educational setting. International Joumal of Educational Development 25: 193-208.

Hannan, MT, Pólos L and Carroll GR (2007) Logics of Organization Theory: Audiences, Codes, and Ecologies. Princeton, US: Princeton University Press.

Haveman HA, Rao H (2006) Hybrid forms and the evolution of thrifts. American Behavioral Scientist 49: 974-986.

Kamps J, Pólos L (1999) Reducing uncertainty: a formal theory of Organizations in Action'. American Journal of Sociology 104: 1774-1810.

Katzenstein P (1985) Small States in World Markets: Industrial Policy in Europe. Ithaca: Cornell University Press.

Kern T (2010) Translating global values into national contexts: the rise of environmentalism in South Korea. International Sociology 25: 869-896.

Marquis C, Battilana J (2009) Acting globally but thinking locally? The enduring influence of local communities on organizations. Research in Organizational Behavior 29: 283-302.

Masuch M, Lapotin P (1996) The disorder of organizational logic - makework among members of bureaucratic organizations. In: Warglien $\mathrm{M}$ and Masuch $\mathrm{M}$ (eds) The Logic of Organizational Disorder. Berlin, New York: Walter de Gruyter, pp. 145-162.

McCune W. Prover9 and Mace4. Theorem-prover software manual and download Available: http://www.cs.unm.edu/ mccune/mace4 (visited on 20.04.2015) 
Meyer JW (2000) Globalization: sources and effects on national states and societies. International Sociology 15: 233-248.

Meyer JW, Boli JT, George M and Ramirez FO (1997) World society and the nation-state American Journal of Sociology 103: 144-181.

Meyer JW, Bromley P and Ramirez FO (2010) Human rights in social science textbooks: cross-national analysis, 1970-2008. Sociology of Education 83: 111-134.

Minkoff DC (2002) The emergence of hybrid organizational forms: Combining identitybased service provision and political action. Non-Profit and Voluntary Sector Quarterly 31: 377401.

Negro G, Hannan MT and Rao H (2010) Categorical contrast and audience appeal: niche width and critical success in winemaking. Industrial and Corporate Change 19: 1397-1425.

Otjes S, Lowery D, Gherghina S, Witteloostuijn A van, Péli G and Brasher H (2013). Policy agendas and births and deaths of political parties. Party Politics 19: 381-407.

Péli G (2009) Fit by founding, fit by adaptation: Reconciling conflicting organization theories with logical formalization. Academy of Management Review 34: 343-360.

Péli G. (2016) Analyzing complex organizational arguments with logical model building. In: Kuckertz A and Berger E (eds) Complexity in Entrepreneurship, Innovation and Technology Research - Applications of Emergent and Neglected Methods. Berlin: Springer, pp. 139-159.

Rao H, Monin P and Durand R 2005. Border crossing: bricolage and the erosion of categorical boundaries in French gastronomy. American Sociological Review 70: 968-991.

Robertson R, Khonder HH (1998) Discourses of globalization. International Sociology 13:25-40.

Saito H (2011) Cosmopolitan nation-building: The institutional contradiction and politics of postwar Japanese education. Social Science Japan Journal 14: 125-144. 
Schneiberg M, Clemens ES (2006) The typical tools for the job: Research strategies in institutional analysis. Sociological Theory 24: 195-227.

Schofer E, Ramirez FO, Meyer JW (2000) The effects of science on national economic development, 1970 to 1990. American Sociological Review 65: 866-887.

Veltman F (1996) Defaults in update semantics. Journal of Philosophical Logic 25: 221-261.

Zelner B, Henisz W and Holburn C (2009) Contentious implementation and retrenchment in neoliberal policy reform: The global electric power industry, 1989-2001. Administrative Science Quarterly 54: 379-412. 


\section{Notes}

1 This section builds on the excellent review presented in Berry et al. (2009).

${ }^{2}$ At the level of the Soviet society, this case is about the salience of Stalinist orthodoxy that prevented any modernist fraction from growing significant.

${ }^{3}$ The country's current drift towards ideological partitioning has been made possible by an earlier hybridisation: the Turkish society since long has been very much modernised in an instrumental sense. This example highlights the importance of studying the temporal dynamics of globalization in future research.

${ }^{4}$ Logical model building may apply languages based on more sophisticated systems like modal logics (Gamut, 1991) or non-monotonic logics (Veltman, 1996; Hannan, Pólos and Carroll, 2007).

${ }^{5}$ Definition 1 does not tell if pressure is exercised upon a strong or a weak fraction $x$, even though significant fractions might withhold pressure better.

${ }^{6}$ In case of a week player, we'd arrive to a form of partial value accommodation (cf. cell 1).

${ }^{7}$ Here, the mechanism might be a kind of 'inoculation effect' like when injecting weakened bacteria boosts the immune system of the host, a feedback process to be explored in subsequent research.

${ }^{8}$ Literally, $\operatorname{Accomm}(T)$ means that $T$ accommodates other values (see Table 2), which values can only be modernisation values in the present context (Assumption 1). 
Appendix 1. The theorems and their premises in Prover9 format.

Copy/paste the formulae to Prover9 directly to test the theorems, or to play around with them (http://www.cs.unm.edu/ mccune/mace4/).

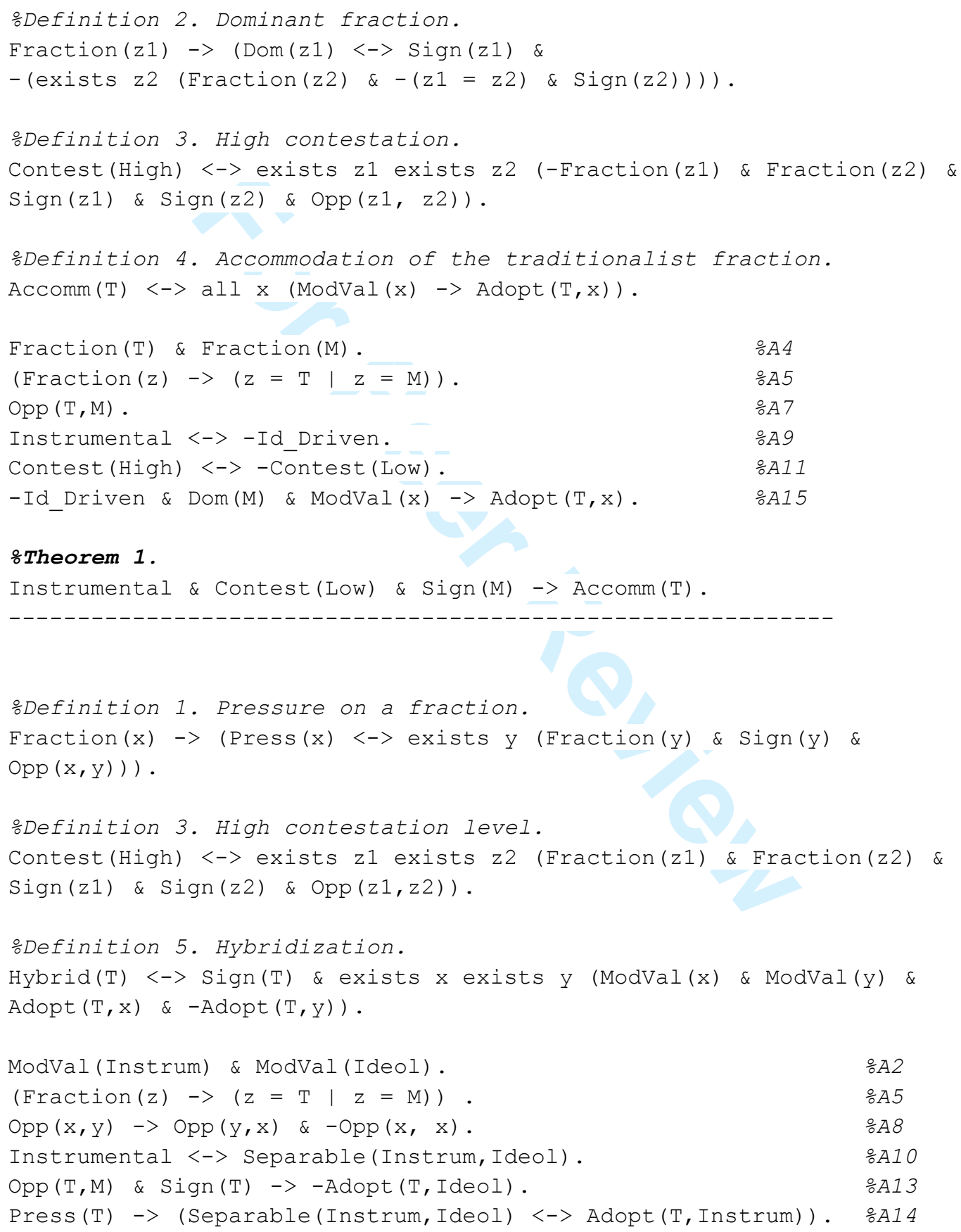




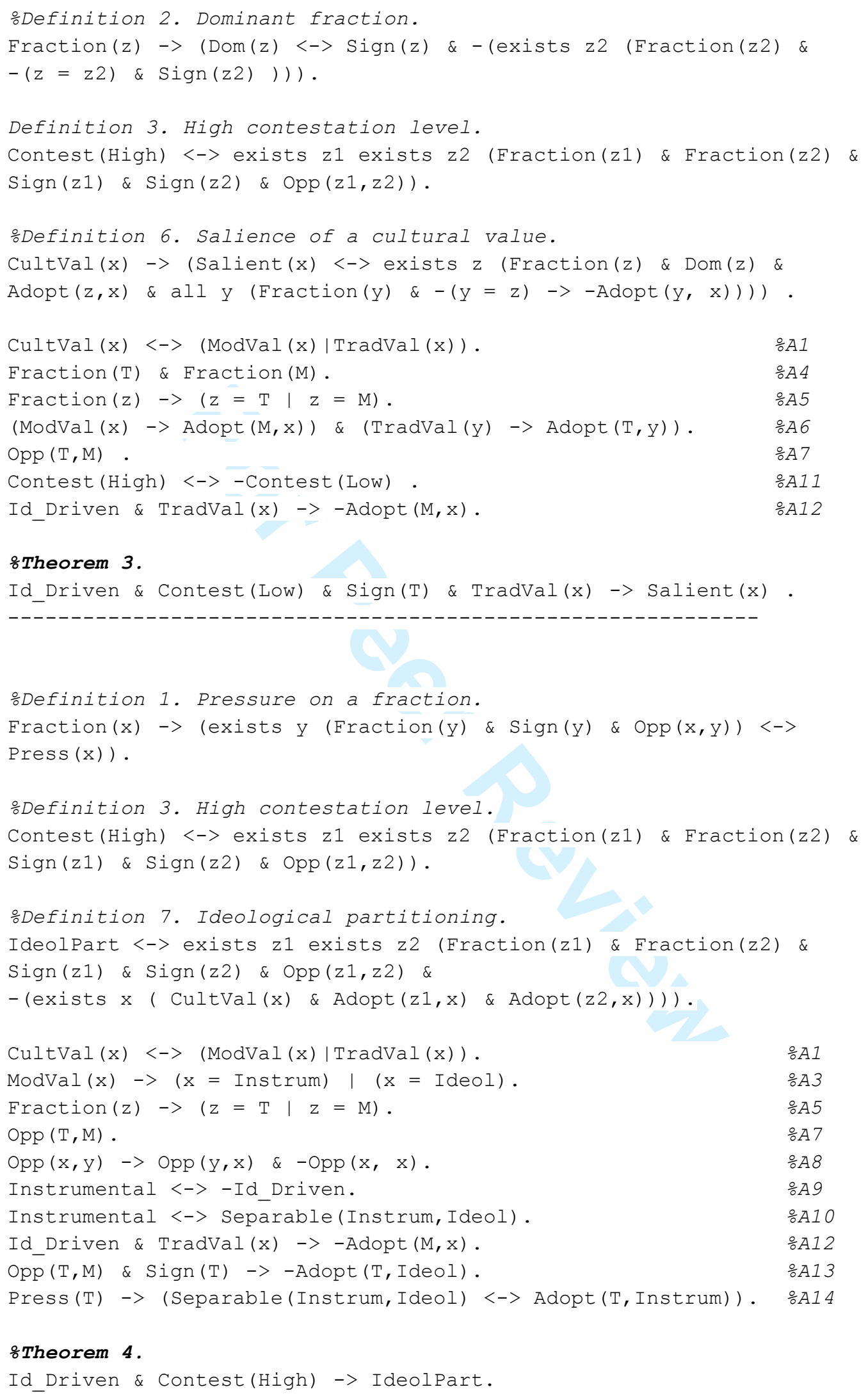


Appendix 2. Non-oppositional contexts.

To demonstrate the possibilities of re-formalization, we briefly address the case of nonoppositional attitudes, sketching how a theory extension could look like with this consideration in place. Let's replace Assumption 7 with its negation, $\neg O p p(T, M)$, calling it Assumption $7 *$. After introducing the $\operatorname{Coop}(x, y)$ predicate with meaning that $x$ and $y$ have mutually cooperative attitudes, we may identify cooperation with the lack of opposition: $\operatorname{Coop}(T, M) \leftrightarrow \neg O p p(T, M)$, Assumption 16. Then, with an additional premise stating that cooperative partners adopt from each other in lack of extreme ideological conditions and with a formal definition on blending, we can derive the case of blending (cell 1, Table 1) as a new theorem. Blending takes place when the two fractions mutually accommodate to each other. Interestingly, we would also find that the globalisation values of the dominant moderniser fraction become also salient in that case (see Definition 6). So under this new setting, the same outcome in cell 1 represents salience and blending simultaneously. Let's assume now that (unlike in Theorem 1) it is the local traditionalist fraction that assumes dominant role. Then we would find that blending can even combine with a peaceful version of traditionalist value dominance. This is the case, for example, when the local society learns from the globaliser newcomers and also assimilates them.

Note that the new Assumption 16 also carries some constraints that can possibly be released. One is that its 'if and only if' structure excludes in-between attitudes, for example neutrality. A weakened Assumption 16* that cancels one implication direction would allow for non-oppositional but still non-cooperative, passive attitudes: $\operatorname{Coop}(T, M) \rightarrow \neg O p p(T, M)$. An intriguing topic for theory building would be exploring the dynamics through which such a non-hostile, neutral attitude to globalisation can develop into acceptance and cooperation; or even into induced opposition when the ideological character of the incoming globalisation impact is irritatingly over-emphasised. These possibilities should be first explored with usual theoretical discourse, in natural language. Still, the reader may note from this sketch how established logic machinery can help perceiving varieties of theoretical ramifications. Another constraint brought about by the if and only if nature of new Assumption 16 would be that the $\operatorname{Coop}(T, M)$ statement inherits the symmetry of $O p p(T, M)$. This constraint would also be released with Assumption 16* in place, opening additional prospects for research. For example, globalisation-proponents then might be cooperative while locals not; or the other way around, as it is the case with aggressive 
modernisers. Once sound theoretical arguments emerge on these contexts, logical formalization can step in, helping to push the knowledge frontier a bit further. 